\title{
The biotic effects of climate change
}

\author{
Adrian M Lister
}

Adrian M Lister

$\mathrm{PhD}$, Research

Leader, Natural

History Museum,

London

Clin Med

2009;9:14-15
ABSTRACT - Humans are part of the biosphere and dependent upon it. The impact of climate change on 'ecosystem services' is therefore of extreme concern. Many studies demonstrate unequivocally that global warming is shifting the distribution of animal and plant species, affecting the composition not only of natural ecosystems but of agricultural ones as well, and also altering the range and impact of pathogenic organisms. The future trajectory of such complex processes is hard to map accurately, but even conservative estimates predict substantial species extinctions and changes in regional productivity. There is still a chance to significantly mitigate these effects, however, if urgent measures are taken. The biotic effects of climate change are strongly exacerbated by ongoing habitat destruction, which no less urgently needs to be halted or reversed by concerted international action. In terms of its rate and its human causation, the present crisis is not analogous to past 'natural' events.

The living world is the life-support system of the human species. Living organisms provide the food we eat and the oxygen we breathe. They also include pathogens and their vectors, and the microbes that can poison our water. Anything that is likely to have a major impact on the world's ecosystems is therefore of extreme concern in the areas of human health and well-being.

Studies of a range of living organisms have demonstrated significant shifts in the distributions of many species in recent decades. The predominantly poleward direction of these movements - at an average rate of around $6 \mathrm{~km}$ per decade - strongly implicates climatic warming as the driving factor. ${ }^{1}$ If, very broadly, habitat belts shift north and south away from the equator, then the polar ecosystems, such as the northern tundra, are among the most vulnerable, as their occupants have 'nowhere else to go'. A similar fate awaits species restricted to mountainous regions, as their response to warming is to move higher in altitude - until they reach the top.

Other studies illustrate the subtler, but no less significant, ways in which species can be affected by climate change. Amphibians, worldwide, are in dramatic decline: over 400 species are 'critically endangered' and more than 100 more are thought already to be extinct. The latter include 70 or so species of harlequin frog (Atelopus) in the Central American tropics, whose demise has been attributed to a pathogenic fungus (Batrachochytrium dendrobatadis). There is good evidence that increasing temperatures in the amphibians' highland habitats have shifted toward the growth optimum of the fungus, encouraging outbreaks. $^{2}$ This example not only illustrates the sensitivity of the biota and the complexity of its response to climate change, but also has obvious implications for the indirect effects of climate change on pathogens of all species, including humans.

Climatic projections for the 21 st century, under a variety of carbon-emission scenarios, have been used to model the likely further responses of living species. Studies on European and African birds, for example, indicate changes of $1,000 \mathrm{~km}$ or more in the boundaries of many species, a decline in their average range, and extinction, especially those of restricted current range or specialised adaptation. ${ }^{3}$ A broader study covering a wide range of organisms, from mammals to insects to plants, found that anything from $18-35 \%$ of species globally may be 'committed to extinction' by 2050, the upper and lower limits representing the effects of minimal and maximal climate change scenarios. ${ }^{4}$ The positive aspect of this gloomy message is that significant species extinctions can still be avoided if the minimal estimates can be met.

Some parts of the world will clearly be more impacted than others. For Australian tropical rainforests, for example, an environmental catastrophe is predicted if global temperatures increase by more than $2^{\circ} \mathrm{C}$, with widespread extinctions across endemic vertebrates as their core environment is severely reduced or lost. ${ }^{5}$

The effects of climate change will be strongly exacerbated by other human impacts on the environment. The loss of natural habitats to urbanisation and agriculture, even at present levels, creates barriers preventing species from dispersing to displaced areas of suitable habitat, even if they exist. Other factors, such as bushmeat hunting and pollution, threaten species so that they are more sensitive to the additional pressure of climate change.

As a palaeontologist, I am often confronted by the argument that, since the world has been through many cycles of climatic and biotic change, the present crisis is 'natural' or even 'doesn't matter'. Even setting aside the obviously unique factor that the present crisis has been caused by humans, I do 
not accept that viewpoint. First, the fossil record shows that, at normal 'background' levels of extinction, evolution was able to keep pace and generate new species to replace those lost so that, overall, there has been an increase in biodiversity since the Cambrian explosion 530 million years ago. It is almost certain that the rate of current change is too rapid for most species to respond by evolutionary innovation. Second, previous episodes of mass extinction have been followed by a gap of 10 to 20 million years while the biosphere recovered. We are entitled to take an anthropocentric view and conclude that we are not prepared to wait that long. Third, even in comparison with the more recent past, climate change is predicted in the 21 st century to take global temperatures above anything seen in at least the past million years. That period of time is the one in which the human species evolved. We are in danger of destroying the context in which we arose and to which we are adapted.

\section{References}

1 Parmesan C, Yohe G. A globally coherent fingerprint of climate change across natural systems. Nature 2003;421:37-42.

2 Pounds JA, Bustamante M, Coloma L et al. Widespread amphibian extinctions from epidemic disease driven by global warming. Nature 2006;439:161-7.

3 Huntley B, Collingham Y, Green R et al. Potential impacts of climate change upon geographical distributions of birds. Ibis 2006;148:8-28.

4 Thomas CD, Cameron A, Green R et al. Extinction risk from climate change. Nature 2004;427:145-8.

5 Williams SE, Bolitho EE, Fox S. Climate change in Australian tropical rainforests: an impending environmental catastrophe. Proc $R \operatorname{Soc} B$ 2003;270:1887-92. 